\begin{tabular}{|l|lll|}
\hline & Journal : Small 11205 & Dispatch : 29-12-2015 & Pages : 18 \\
& Article No. : 1224 & $\square$ LE & $\square$ TYPESET \\
MS Code : SOCI-D-15-00757 & $\checkmark \mathrm{CP}$ & $\checkmark$ DISK \\
\hline
\end{tabular}

\title{
3 Examining the Independent Effect of Social Support 4 on Unmet Mental Healthcare Needs Among Canadians: 5 Findings from a Population-Based Study
}

\author{
6 Philip Baiden ${ }^{1} \cdot$ Wendy den Dunnen ${ }^{2} \cdot$ Barbara Fallon $^{1}$
}

8 C Springer Science+Business Media Dordrecht 2015

9 Abstract Although studies have identified social support as an important social deter10 minant of health, few studies in Canada have actually examined the contributory role of 11 social support in understanding access to mental healthcare services. The objective of this 12 study was to examine the independent effect of social support on unmet mental healthcare 13 needs among adult Canadians after taking into account predisposing, enabling, and need 14 factors of the behavioural model of healthcare service use. This study uses data from the 152012 Canadian Community Health Survey-Mental Health. A sample of 3857 respondents 16 aged 20 years and older with some form of perceived mental healthcare needs was ana17 lyzed using binary logistic regression with unmet mental healthcare needs as the outcome variable. The study found that of the 3857 respondents, close to a third (31.9\%) had unmet needs. Results from the binary logistic regression revealed that social support had a significant independent effect on unmet mental healthcare needs. For each one unit increase in social support, the odds of a respondent having unmet needs were predicted to decease by a factor of $10 \%$ (AOR 0.90, $p<.001,95 \%$ CI $0.89-0.92$ ), net the effect of predisposing, enabling, and need factors. Other factors associated with having unmet mental health care needs include: younger age, income, suicidal ideation, anxiety disorder, and adverse childhood experience. It is important to develop mental healthcare policies and programs that are appropriate and meet the needs of individuals with mental health-related problems and who are without adequate social support.

28 Keywords Unmet mental healthcare needs - Social support · Mental health · Canadian 29 Community Health Survey

30

A1

Philip Baiden

A2

philip.baiden@mail.utoronto.ca

A3 1 Factor-Inwentash Faculty of Social Work, University of Toronto, 246 Bloor Street West, Toronto, A4 ON M5S 1V4, Canada

A5 2 School of Psychology, University of Ottawa, 136 Jean Jacques Lussier, Vanier Hall, Ottawa, A6 ON K1N 6N5, Canada 


\begin{tabular}{|l|lll|}
\hline & Journal : Small 11205 & Dispatch : 29-12-2015 & Pages : 18 \\
& Article No. : $\mathbf{1 2 2 4}$ & $\square$ LE & $\square$ TYPESET \\
MS Code : SOCI-D-15-00757 & $\checkmark$ CP & $\checkmark$ DISK \\
\hline
\end{tabular}

P. Baiden et al.

\section{Introduction}

The Canada Health Act seeks to facilitate access to healthcare services for its citizens. Section 3 of the Act states "it is hereby declared that the primary objective of Canadian health care policy is to protect, promote and restore the physical and mental well-being of residents of Canada and to facilitate reasonable access to health services without financial or other barriers" (Canada Health Act 1984, c.6, s. 3). However, various studies (e.g., Rhodes and Bethell 2008; Steele et al. 2007; Sunderland and Findlay 2013) have shown that there are many Canadians with unmet mental healthcare needs. Similar to a burden of disability and chronic pain, the impact of unmet mental healthcare needs can place a significant burden on individuals and their families, the economy in terms of absenteeism and loss of productivity, and the Canadian healthcare system, as untreated mental health conditions could result in chronic conditions, which then requires an increase in government spending on mental health services.

A widely used measure of unmet healthcare needs is the percentage of individuals in a population who are without access to appropriate healthcare services when they need them the most (Baiden et al. 2014; Carr and Wolfe 1976; Sibley and Glazier 2009). For the purposes of this study, unmet needs was defined to mean the presence of mental healthcare needs (i.e., information, medication, counseling, and other), and the absence of services towards those needs. Using data from the 2002 Canadian Community Health SurveyMental Health and Wellbeing (CCHS 1.2), Steele et al. (2007) found that $23 \%$ of Canadians who met the criteria for anxiety or affective disorder felt they could not receive services. Rhodes and Bethell (2008) also found that about one in two Canadians with suicidal ideation did not receive mental healthcare services within the past 12 months. Furthermore, a recent study by Sunderland and Findlay (2013) found that $17 \%$ of Canadians aged 15 and older had unmet mental healthcare needs.

Previous studies have identified factors influencing unmet needs based on the behavioural model of healthcare services developed by Aday and Andersen (1974). The model hypothesizes that healthcare service use is influenced by predisposing, enabling, and need factors (Aday and Andersen 1974; Andersen 1995). Predisposing factors relate to an individual's tendency to use healthcare services and include demographic factors, such as age, gender, and race/ethnicity. Enabling factors refer to the resources individuals have and can draw on in obtaining healthcare services when needed. Factors such as marital status, income, and level of education, are generally considered as enabling factors in understanding healthcare service use. In the model, need factors encompass the level of illness and individual's psychosocial level of functioning, such as mental health condition, abuse and trauma history, and chronic condition that affects healthcare service use (Aday and Andersen 1974; Andersen and Newman 2005).

Although the behavioural model is generally used to study healthcare service use and unmet needs, there are some known limitations with this model in that it pays less attention to psychosocial and contextual factors (Bradley et al. 2002). Psychosocial factors, such as sense of emotional security, well-being, emotional bonding, interpersonal attachment, and contextual factors, such as having warm and trusting relationship with others and social support, have not been adequately explored as aspects of the behavioural model of healthcare service use. Perceived availability of some of these factors may play an important role in increasing access to resources in general (Cohen 1988; Cohen and Lemay 2007; Cohen and Wills 1985; Gerich 2014) and healthcare in particular (Lin et al. 2015). 


\begin{tabular}{|l|lll|}
\hline & Journal : Small 11205 & Dispatch : 29-12-2015 & Pages : 18 \\
Article No. : 1224 & $\square$ LE & $\square$ TYPESET \\
MS Code : SOCI-D-15-00757 & $\checkmark \mathrm{CP}$ & $\checkmark$ DISK \\
\hline
\end{tabular}

Examining the Independent Effect of Social Support on Unmet...

\section{$77 \quad$ 1.1 The Role of Social Support as a Theoretical View}

78

79

80

81

82

83

84

85

86

87

88

89

90

91

92

93

94

95

96

97

98

99

100

101

102

103

104

105

106

107

108

$10{ }_{\mathrm{AQ1}}$

Social support is generally conceptualized as the amount of perceived support one has with family, friends, and loved ones. According to Cohen and Wills (1985), social support is an important factor in determining access to resources; as the protective role of social support is cognitively mediated by an individual's interpretation of life stressors or knowledge of coping resources he/she perceives to be available to help him/her to meet his/her needs. Conceptually, social support consists of emotional, tangible/instrumental, and informational support (House and Kahn 1985; Kahn and Antonucci 1980). Emotional support includes having someone to talk to, having close relationships with family and friends, and feeling cared for and loved (Kahn and Antonucci 1980; Sarason et al. 1983, 1987). Tangible/instrumental support relates to having someone who provides financial support, time, or other resources; having someone to count on in times of crisis; and having someone to help with instrumental activities of daily living, such as getting to appointments, groceries, cooking, cleaning, or paying phone bills (Berkman and Krishna 2014; Cutrona and Russell 1990). Lastly, informational support consists of exchanges of practical information, such as providing the name of a good doctor, tips on new healthcare centres, new medications; having someone to have important life discussions with; and having support for one's actions or statements (Coomber and King 2012; House and Kahn 1985; Pierce et al. 1996).

There are two main pathways or mechanisms in which social support can help explain unmet mental healthcare needs. Cohen and Wills (1985) characterized these as the buffering and the main-effect pathways. The buffering pathway posits that social support acts as a buffer to protect the health of individuals or individuals who are going through stressful life events (Cohen and Wills 1985). First, social support can help enhance an individual's self-esteem if the individual perceives that he/she is loved and cared for despite his/her personal difficulties, feels socially accepted, and emotionally secured. Second, social support may attenuate how individuals cope with stressful life events following their occurrence. The perceived notion that others are available to provide support when needed may help an individual cope with loneliness and enhance an individual's ability to cope with pathological outcomes following stressful life event (Cohen and Wills 1985). An impressive body of literature has found feelings of loneliness and helplessness to be associated with decreased coping abilities among individuals with mental health problems (Cacioppo et al. 2006; Fiori and Consedine 2013; Kunst et al. 2010), breast 11 AQ2 et al. 2015; Hawkley et al. 2010; McLaughlin et al. 2010). Loneliness and social isolation 112 have also been linked to low satisfaction with life (Kong and You 2013), psychiatric 113 morbidity (Shevlin et al. 2015) and mortality (Holt-Lunstad et al. 2015; Newall et al. 2013; 114 Patterson and Veenstra 2010).

115 The main-effect pathway proposes that access to social resources provides protection to 116 an individual irrespective of whether an individual is experiencing stressful life events 117 (Cohen and Wills 1985). Unlike emotional support, tangible/instrumental and informa118 tional support may influence access to mental healthcare service use, as these types of 119 support enhance access to information, material goods, and resources (Berkman and 120 Krishna 2014). For example, Granovetter's (1973) study of the strength of weak ties 121 illustrates how tangible/instrumental and informational support enhances an individual's 122 access to resources. Granovetter (1973) discovered that individuals looking for employ123 ment opportunities were more likely to find out about new jobs through personal contacts 
than any other means. More recently, scholars have found an association between higher levels of social support and better access to healthcare and public housing (Distelberg and Taylor 2013). Also, Lin et al. (2015) examined the link between emotional support and access to healthcare among adults living with HIV in rural China and found that each additional increase in emotional support results in a 0.29 increase in access to healthcare, net the effect of demographic characteristics, socioeconomic factors, and self-perceived physical health status. Taken together, these findings indicate that social support could provide resources necessary to access mental healthcare when needed. Consequently, individuals with fewer social supports may be less likely to benefit from the added advantage of social support or may not be aware of where tr seek appropriate healthcare when needed.

With respect to the link between social support and mental health, various researchers using either longitudinal or cross-sectional designs have found a positive effect of social support in improving coping abilities with stressful life events such as childhood abuse (Kang 2012; Sperry and Widom 2013), marital loss (Hewitt et al. 2012), as well as severe mental illness (Davis and Brekke 2014; Langeland and Wahl 2009). Adjusting for potential confounders, Rowe et al. (2006) found that higher perceived social support, such as feeling worthwhile to family and friends and satisfaction with one's relationships with others, were significantly associated with lower odds of suicidal ideation. Similar results have also been found by Gallagher et al. (2014) in a clinical sample of adolescents with suicidal ideation. Furthermore, Hansen and Aranda (2012) examined data from 235 adult Latinos living in Los Angeles County and found that both emotional and instrumental support moderated the link between linguistic acculturation and mental health needs.

\subsection{Current Study}

Notwithstanding the growing social epidemiological evidence (see e.g., Cutrona 1984; Gerich 2014; Huurre et al. 2007; Ikeda and Kawachi 2010; Ilse et al. 2015; Kawachi and Berkman 2001; Link and Phelan 1995; Salonna et al. 2012) showing social support as an important social determinant of health, the independent effect of social support on unmet mental healthcare needs in Canada has not been adequately examined. Therefore, this study contributes a new dimension and perspective to the behavioural model of healthcare service use by examining the independent effect of social support on unmet mental healthcare needs. Using data from the 2012 Canadian Community Health Survey-Mental Health (CCHS-MH), the objective of this study was to examine the independent effect of social support on unmet mental healthcare needs among adult Canadians after taking into account predisposing, enabling, and need factors of the behavioural model of healthcare service use. The main hypothesis guiding this study was that there would be an independent effect of social support on perceived mental healthcare needs after adjusting for predisposing, need, and enabling factors.

\section{Data and Methods}

\section{$163 \quad 2.1$ Data}

164 Data for this study came from the 2012 CCHS-MH Public Use Microdata Files (PUMF). A 165 detailed description of the 2012 CCHS-MH has been provided elsewhere (see e.g., Baiden 


\begin{tabular}{|l|lll|}
\hline & Journal : Small 11205 & Dispatch : 29-12-2015 & Pages : 18 \\
& Article No. : $\mathbf{1 2 2 4}$ & $\square$ LE & $\square$ TYPESET \\
MS Code : SOCI-D-15-00757 & $\checkmark$ CP & $\checkmark$ DISK \\
\hline
\end{tabular}

Examining the Independent Effect of Social Support on Unmet...

166 et al. 2015). In brief, the CCHS-MH is a cross-sectional survey that gathers information on 167 factors that influence mental health through a multidisciplinary approach focusing on 168 social and economic determinants of health. The survey covers individuals aged 15 and above residing in the 10 provinces and uses a multistage cluster sampling design with a random sampling method to select a sample that is representative of the Canadian population (Statistics Canada 2013). The main objectives of the CCHS-MH among others were to: "(1) assess the mental health status of Canadians on both illness and positive mental health continuums through selected mental and substance disorders, mental health problems, and well-being, and (2) assess timely, adequate, and appropriate access to and utilization of formal and informal mental health services and supports, as well as perceived needs" (Statistics Canada 2013, p. 3).

In the 2012 CCHS-MH dataset, there were 25,113 (unweighted) respondents which represent $28,314,716$ of the Canadian population. Complete data on all the variables included in the multivariate analysis were available for 19,709 respondents aged $20-80$ years. Of this, 15,852 respondents $(80.4 \%)$ did not have mental healthcare needs, whereas $3857(19.6 \%)$ had self-identified mental healthcare needs that were either fully met $(n=2629)$ or unmet $(n=1228)$. For the purposes of this study, respondents who did not have mental healthcare needs were excluded from the analysis. Therefore, the sample size analyzed in this study consists of 3857 respondents who had some perceived mental healthcare needs. To produce a sample that is equal to the original sample size and representative of the Canadian population, the population weight was adjusted by dividing each weight by the sum of weights and then multiplied by the sample size. This was done to maintain the original sample size while, at the same time, keeping the weighting structure recommended by Statistics Canada. All analyses are based on the weighted data.

\subsection{Outcome Variable}

191 The outcome variable examined in this study was perceived mental healthcare needs within

192 the past 12 months. The original variable grouped respondents into four categories based 193 on whether mental healthcare need was reported (i.e., information, medication, counseling, 194 and other), and if so, whether the needs were met (i.e., all perceived mental healthcare 195 needs were met), partially met (i.e., received mental healthcare but not enough), or unmet 196 (i.e., did not receive mental healthcare that was needed). Those whose needs were fully met 197 were coded as 0 , and those whose mental healthcare needs were partially met or not met at 198 all were considered as having unmet mental healthcare needs and were coded as 1.

\section{$199 \quad 2.3$ Explanatory Variables}

200 The main explanatory variable examined in this study was social support and was measured as an interval/ratio variable based on the revised version of the Social Provision Scale developed by Cutrona (1984) and refined by Caron (1996). The revised Social Provision Scale is a 10-item measure that assesses the availability of social support to an individual based on his/her perception. Respondents were asked to indicate the extent to which they agree with the following statements: e.g., "There are people I can depend on to help me if I really need it", "There are people I can count on in an emergency," etc. Each item was rated on a four-point Likert scale ranging from 1 (strongly agree) to 4 (strongly disagree). However, for ease of interpretation, each item was reverse coded such that higher scores indicated greater endorsement. Scores on the social support scale range from 10 to 40 with higher scores indicating greater perception of the respondent having received 


\begin{tabular}{|l|lll|}
\hline & Journal : Small 11205 & Dispatch : 29-12-2015 & Pages : 18 \\
& Article No. : 1224 & $\square$ LE & $\square$ TYPESET \\
MS Code : SOCI-D-15-00757 & $\checkmark \mathrm{CP}$ & $\checkmark$ DISK \\
\hline
\end{tabular}

P. Baiden et al.

or being able to receive social support. The revised social provision scale has been found to be a valid measure of social support with strong internal consistency (Caron 1996; Fleury et al. 2013). In this study, factor analysis performed on the 10-items revealed that the items loaded on a single factor with an eigenvalue of 6.229. Corrected item-total correlations for the 10-items range from 0.67 to 0.80 and the Cronbach's alpha of reliability was 0.93 , indicating excellent reliability of the social support scale among respondents with perceived mental healthcare needs.

\subsection{Control Variables}

Control variables examined in this study include predisposing, enabling, and need factors. Predisposing factors include: age (20-29 years, 30-39 years, 40-49 years, 50-59 years, and 60 years and above), gender (male vs. female), and immigrant status (non-immigrant vs. immigrant). Enabling factors include: marital status (married, common law, formerly married, and single/never married), post-secondary education (no vs. yes) and annual personal income (no income $/<\$ 20,000, \$ 20,000-\$ 29,999, \$ 30,000-\$ 39,999$, $\$ 40,000$ $\$ 49,9999$, and $\$ 50,000$ and above).

Based on the existing literature, this study took into account five measures of need factors including: lifetime suicidal ideation, past 12 months diagnoses of major depressive episode, general anxiety disorder, and substance dependence disorder (alcohol or cannabis dependence), as well as adverse childhood experience. Lifetime suicidal ideation grouped the respondent based on whether he/she ever thought about committing suicide or taking his/her own life. Respondents who answered in the affirmative were coded as 1 and those who answered in the negative were coded as 0 . Each of the three mental health diagnoses were also measured as a binary variable and coded 1, if the respondent was diagnosed within the past 12 months; otherwise, it was coded as 0 . These mental health and substance dependence variables were determined based on the rigorous WHO version of the Composite International Diagnostic Interview (WHO-CIDI), a structured diagnostic interview that generates diagnosis according to the Diagnostic and Statistical Manual of Mental Disorders, Fourth Edition (DSM-IV) and the International Classification of Disease (ICD10) (Statistics Canada 2014).

Lastly, adverse childhood experience was measured using six questions that ask respondents about things that may have happened to them before age 16, either in school, in the neighborhood, or in the family. Respondents were asked how many times: (1) did you for instance witnessed domestic violence? (2) were you slapped in the face, hit or spanked by an adult? (3) were you pushed, grabbed, or shoved? (4) were you physically attacked (kicked/bitten/punched/choked/burned)? (5) did you experience forced or attempted forced sexual activity? and (6) did you experience unwanted sexual touching, kissing, or fondling? (Statistics Canada 2014). Responses to each question were coded as 1 (never) to 5 (more than 10 times). Respondents whose responses were coded as 2, 3, 4, or 5 were considered to have experienced the event at least once and respondents whose responses were coded as 1 were considered not to have experienced the event. A sum of adverse childhood experience score was created (range 0-6) to arrive at the number of childhood adversities experienced before age 16. Due to the non-normal distribution of scores on adverse childhood experience, scores of 3 or more were combined into one category $(0,1,2$, and $\geq 3)$. 


\begin{tabular}{|l|lll|}
\hline & Journal : Small 11205 & Dispatch : 29-12-2015 & Pages : 18 \\
Article No. : 1224 & $\square$ LE & $\square$ TYPESET \\
MS Code : SOCI-D-15-00757 & $\checkmark \mathrm{CP}$ & $\checkmark$ DISK \\
\hline
\end{tabular}

Examining the Independent Effect of Social Support on Unmet...

\subsection{Data Analysis}

The data analytic strategy included the use of descriptive, bivariate, and multivariate techniques. Multivariate analysis was conducted using binary logistic regression to examine the independent effect of social support on unmet needs after adjusting for predisposing, enabling, and need factors. Binary logistic regression was chosen because the outcome variable was measured as a binary variable and the explanatory variables were measured as both categorical and interval/ratio variables (Hosmer and Lemeshow 2000; Tabachnick and Fidell 2007). Two logistic regression models were fitted with predisposing, enabling, and need factors entered in Model 1 . Model 2 was fitted to assess the independent effect of social support on unmet needs over and above all the variables included in Model 1.

Model fitness was assessed using the omnibus Chi square tests of model coefficient, the percentage of respondents correctly classified as having unmet needs versus no unmet needs, as well as sensitivity and specificity for each model. The classification cut-off was adjusted to reflect the proportion of respondents with unmet needs in the sample. Sensitivity is the probability of correctly predicting an event to have occurred when that event actually did occur (i.e., respondent was observed to have unmet needs and was correctly predicted to have unmet needs). On the other hand, specificity is the probability of correctly predicting an event as not having occurred when that event actually did not occur (i.e., respondent was observed to have no unmet needs and was correctly predicted as having no unmet needs) (Fielding and Bell 1997). Nagelkerke pseudo $\mathrm{R}^{2}$ was also examined to determine the amount of variance in unmet needs that can be explained by the set of variables included in each model. However, given that logistic regression does not have the equivalent of an $\mathrm{R}^{2}$ as found in ordinary least square regression (http://www.ats. ucla.edu/stat/spss/output/logistic.htm), we suggest some level of caution when interpreting the Nagelkerke pseudo $\mathrm{R}^{2}$. Adjusted odds ratios (AOR) are reported together with their $95 \%$ confidence intervals $(95 \% \mathrm{CI})$. Variables were considered significant if the $p$ value was $<.05$. All analyses were executed using SPSS version 22 for Windows (SPSS Inc., Chicago, IL, USA).

\section{Results}

\subsection{Sample Characteristics}

Table 1 presents the sample characteristics of the respondents with perceived need for mental healthcare. Of the 3857 respondents with some form of perceived mental healthcare needs, close to a third (31.9\%) had unmet needs. The average social support score among the respondents was $34.68(S D=5.14$, range $10-40)$. For a detailed distribution of all the other variables, see Table 1.

\subsection{Bivariate Results}

Table 2 provides the bivariate results on the relationship between perceived mental healthcare needs and the explanatory variables. With the exception of gender and postsecondary graduates, all the variables examined were significantly associated with unmet needs at the bivariate level. Respondents who were older or had higher income were less 


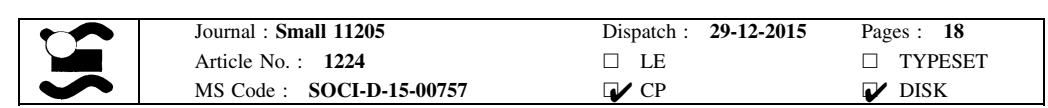

P. Baiden et al.

Table 1 Sample characteristics $(\mathrm{n}=3857)$
Variables

Outcome variable

Perceived mental healthcare needs

Needs fully met

2629 (68.1)

Unmet needs

1228 (31.9)

Explanatory variables

Predisposing factors

Age

20-29 years

687 (17.8)

30-39 years

816 (21.2)

40-49 years

880 (22.8)

50-59 years

814 (21.1)

60 years and above

$660(17.1)$

Gender

Male

1426 (37.0)

Female

2431 (63.0)

Immigrant status

Non-immigrant

3262 (84.6)

Immigrant

595 (15.4)

Enabling factors

Marital status

Married

1741 (45.1)

Common-law relationship

$511(13.2)$

Formerly married

652 (16.9)

Single/never married

953 (24.7)

Post-secondary graduate

No

1290 (33.4)

Yes

2567 (66.6)

Annual personal income

No income $/<\$ 20,000$

951 (24.7)

\$20,000-\$29,999

891 (23.1)

$\$ 30,000-\$ 39,999$

512 (13.3)

$\$ 40,000-\$ 49,999$

$351(9.1)$

$\$ 50,000$ and above

1152 (29.9)

Need factors

Suicidal ideation

No

2524 (65.4)

Yes

1333 (34.6)

Major depressive episode

Not diagnosed

3039 (78.8)

Diagnosed

818 (21.2)

General anxiety disorder

Not diagnosed

3399 (88.1)

Diagnosed 


\begin{tabular}{|l|lll|}
\hline & Journal : Small 11205 & Dispatch : 29-12-2015 & Pages : 18 \\
& Article No. : 1224 & $\square$ LE & $\square$ TYPESET \\
MS Code : SOCI-D-15-00757 & $\checkmark \mathrm{CP}$ & $\checkmark$ DISK \\
\hline
\end{tabular}

Examining the Independent Effect of Social Support on Unmet...

Table 1 continued

\begin{tabular}{|c|c|c|}
\hline & & \\
\hline & Substance dependence & \\
\hline & Not diagnosed & $3684(95.5)$ \\
\hline & Diagnosed & $173(4.5)$ \\
\hline & Adverse childhood experience & \\
\hline & None & $1306(33.9)$ \\
\hline & One & $891(23.1)$ \\
\hline & Two & $515(13.4)$ \\
\hline$\S$ Mean and standard deviation & Three or more & $1145(29.7)$ \\
\hline $\begin{array}{l}\text { was reported for social support } \\
\text { scale }\end{array}$ & Social support, mean $(\mathrm{SD})^{\S}$ & $34.68(5.14)$ \\
\hline
\end{tabular}

296

297

298

299

300

301

302

303

304

305

306

307

308

309

310

311

312

313

314

315

316

317

318

319

320

321

322

323

324

325

326

327

328

likely to report having unmet needs. Respondents who were immigrants or were single/ never married were more likely to report having unmet needs. Also, respondents were more likely to report having unmet needs if they: had suicidal ideation (39.9 vs. $27.6 \%$ ), were diagnosed with a major depressive episode (43.3 vs. $28.8 \%$ ), general anxiety disorder (46.1 vs. $29.9 \%$ ), substance dependence disorder (43.4 vs. $31.3 \%$ ), or experienced two or more adverse childhood events. The results also show that the average social support scores among respondents with unmet needs was significantly lower than the average social support score among respondents with no unmet needs $\left(M_{\text {no unmet needs }}=35.63\right.$ vs. $M_{\text {unmet needs }}=32.66$, OR 0.89, $p<.001,95 \%$ CI 0.88-0.91).

\subsection{Multivariate Logistic Regression Predicting the Odds of Having Unmet Mental Healthcare Needs}

Table 3 shows the multivariate logistic regression result predicting the odds of having unmet needs. Adjusting for all other factors, for each additional unit increase in social support, the odds of a respondent having unmet needs were predicted to decease by a factor of $10 \%$ (AOR $0.90, p<.001,95 \%$ CI $0.89-0.92$ ).

Both age and immigrant status emerged significant in predicting unmet needs in Model 1. However, immigrant status lost its significant effect in Model 2. In Model 2, respondents who are older were less likely to have unmet needs. Gender, education, and marital status were not significant predictors of unmet needs in both Models 1 and 2. In Model 2, odds were about $33 \%$ lower for respondents who earned \$20,000-\$29,999 (AOR 0.67, $p<.001,95 \%$ CI $0.54-0.82)$ and $35 \%$ lower for respondents who earned $\$ 30,000$ $\$ 39,999$ (AOR 0.65, $p<.001,95 \%$ CI 0.50-0.83) to report having unmet needs both when compared to respondents with no income or who earned $<\$ 20,000$.

All the need factors included in Model 1 except substance dependence were significantly associated with the odds of having unmet needs. However, major depressive episode lost its significant effect in Model 2. In Model 2, respondents with lifetime suicidal ideation were 1.2 times more likely to report having unmet needs when compared to respondents with no lifetime suicidal ideation ( $A O R$ 1.20, $p<.05,95 \%$ CI 1.03-1.41). Respondents who were diagnosed with anxiety disorder were 1.38 times more likely to report having unmet needs when compared to their counterparts with no such diagnosis (AOR 1.38, $p<.01$, $95 \%$ CI 1.10-1.73). Respondents who experienced two adverse childhood experiences were 1.39 times more likely to report having unmet needs (AOR $1.39, p<.01$, $95 \%$ CI 1.11-1.76) and respondents who experienced three or more adverse childhood 


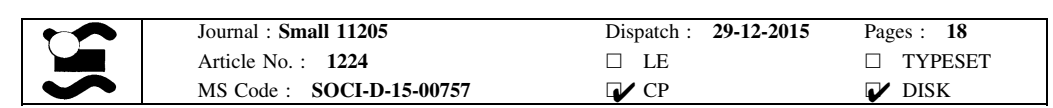

P. Baiden et al.

Table 2 Bivariate association between perceived mental health care need and categorical explanatory variables $(\mathrm{n}=3857)$

\begin{tabular}{lll}
\hline Variables & $\begin{array}{l}\text { Needs met } \\
\mathrm{n}(\%)\end{array}$ & $\begin{array}{l}\text { Unmet needs } \\
\mathrm{n}(\%)\end{array}$ \\
\hline
\end{tabular}

Predisposing factors

Age

$$
\begin{aligned}
& \text { 20-29 years } \\
& 30-39 \text { years } \\
& 40-49 \text { years } \\
& 50-59 \text { years } \\
& 60 \text { years and above }
\end{aligned}
$$

Gender

Male

Female

Immigrant status

Non-immigrant

Immigrant

Enabling factors

Marital status

Married

Common-law relationship

Formerly married

Single/never married

Post-secondary graduate

No

Yes

Annual personal income

No income/ $<\$ 20,000$

$\$ 20,000-\$ 29,999$

$\$ 30,000-\$ 39,999$

$\$ 40,000-\$ 49,999$

$\$ 50,000$ and above

Need factors

Suicidal ideation

No

Yes

Major depressive episode

Not diagnosed

Diagnosed

General anxiety disorder

Not diagnosed

Diagnosed

$2382(70.1)$

Substance dependence

Not diagnosed

Diagnosed
$1828(72.4)$

$801(60.1)$

2164 (71.2)

464 (56.7)

247 (53.9)

$439(63.9)$
$562(68.9)$
$551(62.7)$
$563(69.1)$
$514(77.9)$

966 (67.7)

1662 (68.4)

$2252(69.0)$

$1230(70.6)$

348 (68.1)

$440(67.5)$

$610(64.0)$

869 (67.4)

1760 (68.6)

548 (57.6)

633 (71.0)

378 (73.8)

$246(70.1)$

824 (71.5)

$2531(68.7)$

98 (56.6)

$248(36.1)$
$254(31.1)$
$328(37.3)$
$252(30.9)$
$143(22.1)$

460 (32.3)

768 (31.6)

1010 (31.0)

219 (36.8)

1.00

$1.30(1.08-1.56)^{* * *}$

$511(29.4)$

1.00

163 (31.9)

$1.12(0.91-1.39)$

212 (32.5)

$1.16(0.96-1.41)$

343 (36.0)

1.35 (1.14-1.60)***

421 (32.6)

1.00

807 (31.4)

0.95 (0.82-1.09)

403 (42.4)

1.00

258 (29.0)

$0.55(0.46-0.67) * * *$

134 (26.2)

$0.48(0.38-0.61)^{* * *}$

105 (29.9)

$0.58(0.45-0.76) * * *$

328 (28.5)

$0.54(0.45-0.65)^{* * *}$

696 (27.6)

1.00

532 (39.9)

$1.74(1.52-2.01)^{* * *}$

874 (28.8)

1.00

354 (43.3)

$1.89(1.61-2.21)^{* * *}$

1017 (29.9)

1.00

211 (46.1)

$2.01(1.65-2.44) * * *$

1154 (31.3)

1.00

75 (43.4)

$1.67(1.23-2.27) * * *$ 


\begin{tabular}{|l|lll|}
\hline & Journal : Small 11205 & Dispatch : 29-12-2015 & Pages : 18 \\
& Article No. : 1224 & $\square$ LE & $\square$ TYPESET \\
MS Code : SOCI-D-15-00757 & $\checkmark \mathrm{CP}$ & $\checkmark$ DISK \\
\hline
\end{tabular}

Examining the Independent Effect of Social Support on Unmet...

Table 2 continued

\begin{tabular}{llcl}
\hline Variables & $\begin{array}{l}\text { Needs met } \\
\mathrm{n}(\%)\end{array}$ & $\begin{array}{l}\text { Unmet needs } \\
\mathrm{n}(\%)\end{array}$ & OR (95\% CI) \\
\hline $\begin{array}{l}\text { Adverse childhood experience } \\
\text { None }\end{array}$ & $958(73.4)$ & $348(26.6)$ & 1.00 \\
One & $641(72.0)$ & $249(28.0)$ & $1.07(0.89-1.30)$ \\
Two & $319(61.9)$ & $196(38.1)$ & $1.69(1.36-2.10)^{* * *}$ \\
Three or more & $710(62.0)$ & $435(38.0)$ & $1.69(1.42-2.01)^{* * *}$ \\
Social support & & $32.66(5.68)$ & $0.89(0.88-0.91)^{* * *}$ \\
Social support & $35.63(4.57)$ & & \\
\hline
\end{tabular}

OR odds ratio

$* p<.05 ; * * p<.01 ; * * * p<.001$

329 experiences were 1.28 times more likely to report having unmet needs (AOR 1.28, $p<.05$,

$33095 \%$ CI 1.05-1.54), both when compared to respondents who did not experience any 331 adverse childhood experience.

\section{$332 \quad 3.4$ Model Diagnosis}

333 The change in the omnibus Chi square tests of model coefficient value for both models was 334 statistically significant suggesting that social support contributed to the model fitness. Both 335 sensitivity and specificity values were quite high indicating a high discriminatory value of 336 the models. For instance, in the model without social support, $63.2 \%$ of the cases were 337 observed to have unmet needs and were correctly predicted as having unmet needs (sen338 sitivity). This percentage improved to $68.4 \%$ with the addition of social support. With 339 respect to specificity, $59.3 \%$ of the respondents were observed as having no unmet needs 340 and were correctly predicted as having no unmet needs in Model 1. The addition of social 341 support in Model 2 saw this percentage improved slightly to $60.2 \%$. The fully adjusted 342 model correctly classified $65.8 \%$ of the cases into unmet needs and no unmet needs, 343 suggesting that all the explanatory variables included in the model performed better than 344 chance in explaining unmet needs.

\section{Discussion}

346 This study examined the independent effect of social support on unmet mental healthcare 347 needs after taking into account predisposing, enabling, and need factors of the behavioural 348 model of healthcare service use. Many of the current findings converge with previous 349 research. The study found that close to one in five Canadians (19.6\%) had mental 350 healthcare needs, of which $68 \%$ had their needs fully met and $32 \%$ had unmet needs. This 351 proportion is fairly comparable to findings reported in other Canadian studies (see e.g., 352 Sunderland and Findlay 2013).

353 Social support was the strongest factor to be associated with unmet needs. Whereas various past studies have established an association between need and enabling factors and unmet needs (e.g., Bryant et al. 2009; Sibley and Glazier 2009), this is one of the few studies to demonstrate the independent effect of social support as a social determinant of 


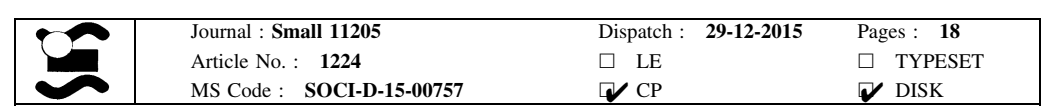

P. Baiden et al.

Table 3 Multivariate logistic regression predicting perceived mental health care needs $(\mathrm{n}=3857)$

\begin{tabular}{lll}
\hline Variables & Model 1 & Model 2 \\
& Need + predisposing + enabling & Fully adjusted model \\
& AOR $(95 \%$ CI $)$ & AOR $(95 \%$ CI $)$ \\
\hline
\end{tabular}

Predisposing factors

Age (20-29 years)

$\begin{array}{lll}30-39 \text { years } & 0.86(0.68-1.09) & 0.76(0.60-0.98)^{*} \\ 40-49 \text { years } & 1.02(0.80-1.30) & 0.79(0.62-1.02) \\ 50-59 \text { years } & 0.84(0.65-1.08) & 0.70(0.54-0.91)^{* *} \\ 60 \text { years and above } & 0.57(0.43-0.76)^{* * *} & 0.44(0.33-0.59)^{* * *} \\ \text { Gender (male) } & 0.98(0.84-1.14) & 1.15(0.98-1.34) \\ \text { Female } & & \\ \text { Immigrant status (no) } & 1.30(1.07-1.58)^{* *} & 1.11(0.91-1.36) \\ \text { Yes } & \end{array}$

Enabling factors

Marital status (married)

Common-law relationship

$0.94(0.74-1.18)$

$1.01(0.80-1.28)$

$1.15(0.94-1.41)$

$1.02(0.83-1.26)$

Formerly married

$1.08(0.88-1.32)$

$0.98(0.80-1.21)$

Post-secondary graduate (no)

Yes

$1.13(0.96-1.32)$

$1.18(1.00-1.39)$

Annual personal income (no income $/<\$ 20,000$ )

$\begin{array}{ll}\$ 20,000-\$ 29,999 & 0.61(0.50-0.75)^{* * * *} \\ \$ 30,000-\$ 39,999 & 0.52(0.41-0.67)^{* * *} \\ \$ 40,000-\$ 49,999 & 0.63(0.48-0.83)^{* * *} \\ \$ 50,000 \text { and above } & 0.64(0.52-0.79)^{* * *}\end{array}$

$0.67(0.54-0.82) * * *$

$0.65(0.50-0.83) * * *$

$0.81(0.67-1.03)$

$0.83(0.67-1.03)$

Need factors

Suicidal ideation (no)

Yes

$1.40(1.20-1.63)^{* * *}$

$1.20(1.03-1.41)^{*}$

Adverse childhood experience (none)

$\begin{array}{ll}\text { One } & 1.01(0.83-1.23) \\ \text { Two } & 1.44(1.15-1.81)^{* * *} \\ \text { Three or more } & 1.34(1.11-1.61)^{* *}\end{array}$

$1.04(0.85-1.27)$

$1.39(1.11-1.76) * *$

$1.28(1.06-1.55)^{*}$

Major depressive episode (not diagnosed)

Diagnosed $1.30(1.08-1.55)^{* *}$

$1.12(0.93-1.35)$

General anxiety disorder (not diagnosed)

Diagnosed

$1.53(1.23-1.90)^{* * *}$

$1.38(1.10-1.73)^{* *}$

Substance dependence (not diagnosed)

Diagnosed

$1.25(0.90-1.74)$

$1.20(0.86-1.69)$

Social support

Nagelkerke $\mathrm{R}^{2}$

0.078

$0.90(0.89-0.92) * * *$

Block Chi square (sig)

221.64 (.001) $d f=21$

0.139

Sensitivity

63.2

$182.36(.001) d f=1$

Specificity

59.3

68.4

60.2 


\begin{tabular}{|l|lll|}
\hline & Journal : Small 11205 & Dispatch : 29-12-2015 & Pages : 18 \\
& Article No. : 1224 & $\square$ LE & $\square$ TYPESET \\
MS Code : SOCI-D-15-00757 & $\checkmark \mathrm{CP}$ & $\checkmark$ DISK \\
\hline
\end{tabular}

Examining the Independent Effect of Social Support on Unmet...

Table 3 continued

\begin{tabular}{lll}
\hline Variables & $\begin{array}{l}\text { Model 1 } \\
\text { Need + predisposing + enabling } \\
\text { AOR }(95 \% \mathrm{CI})\end{array}$ & $\begin{array}{l}\text { Model } 2 \\
\text { Fully adjusted model } \\
\text { AOR }(95 \% \mathrm{CI})\end{array}$ \\
\hline Percentage correctly classified & 61.9 & 65.8
\end{tabular}

Reference categories are identified in brackets

$O R$ odds ratio, $A O R$ adjusted odds ratio

$* p<.05 ; * * p<.01 ; * * * p<.001$

unmet mental healthcare needs. The importance of social support in predicting unmet mental healthcare needs is consistent with the large body of literature highlighting the positive role of social connection on physical and mental health (e.g., Baiden et al. 2014; Cohen 1988; Sarason et al. 1983; Sperry and Widom 2013).

The current findings further support an association between social support and mental health problems as once social support was accounted for, a diagnosis of major depressive episode no longer significantly predicted unmet mental healthcare needs. After accounting for the effect of social support on unmet mental healthcare needs, the presence of an anxiety disorder continued to predict unmet mental healthcare needs, but to a lesser extent. The same was true for suicidal ideation and child maltreatment. Although child maltreatment is not a mental health problem, it is highly associated with mental health. Various scholars have found that child maltreatment is associated with an increased likelihood of mental health problems throughout childhood and adulthood (see e.g., Sperry and Widom 2013).

These findings may suggest a link between social support and mental health problems in understanding unmet mental healthcare needs. This is not surprising given that there is substantial evidence supporting the benefits of social support on mental health problems. For example, research has demonstrated that social support acts as a buffer for stressors and a protective factor against mental health problems (e.g., Cohen 1988; Sperry and Widom 2013). Thus, it is possible that those with social support are better equipped to cope with stressors and mental health problems and/or have fewer perceived stressors and mental health needs than those with lower levels of social support. This inference is in line with the buffering hypothesis posited by Cohen and Wills (1985). More specifically, having social support could enhance an individual's ability to cope with stressors due to the presence of a more optimistic perspective, increased emotional or informational support. The presence of these positive support factors may result in an individual having more resources (e.g., counseling and information about mental health services) and reduced mental health needs (e.g., talking to friends about their concerns and engaging in pleasurable activities with others can help reduce mental health problems such as anxiety and depression), which could then lead to a reduced likelihood of unmet mental healthcare needs.

The finding with respect to the effect of income on unmet mental healthcare needs is interesting. The effect of income is reduced when adjusted for social support. In the model without social support, income had a significant effect on unmet needs. However, after adjusting for social support, respondents who made $\$ 40,000$ and above were not significantly different from their counterparts who made no income or $<\$ 20,000$. This finding further underscores the importance of social support in enhancing access to mental healthcare irrespective of one's income. 


\begin{tabular}{|l|lll|}
\hline & Journal : Small 11205 & Dispatch : 29-12-2015 & Pages : 18 \\
& Article No. : 1224 & $\square$ LE & $\square$ TYPESET \\
MS Code : SOCI-D-15-00757 & $\checkmark \mathrm{CP}$ & $\checkmark$ DISK \\
\hline
\end{tabular}

P. Baiden et al.

The finding that older individuals are less likely to have unmet mental healthcare needs is consistent with previous research examining age and healthcare needs (Baiden et al. 2014; Cavalieri 2013). Expectations about the health and mental healthcare system vary across the lifespan. Younger individuals tend to have higher expectations about health care than the elderly and, thus, are more likely to be dissatisfied with the care received (Cavalieri 2013; Moret et al. 2007; Peck et al. 2004). In addition, older individuals are more likely to be retired and less likely to be raising young children. Thus, it is likely easier for elderly individuals to access healthcare, as well as mental health services, as they are likely to have less daily commitments and demands (Baiden et al. 2014).

Based on the findings of this study, addressing social support may be a useful approach to increase the likelihood that individuals will have their mental healthcare needs met, either by increasing their access to mental health services through informational or tangible support or through the buffering effect of social support on mental health problems, which could then decrease mental health needs (Sperry and Widom 2013). Thus, it is important to address social support challenges with individuals who have mental health needs. Improving social support as part of mental healthcare for individuals with mental health concerns is already a well-established practice (see e.g., Ammerman et al. 2014; LaRocca and Scogin 2015; Siskind et al. 2012). It is possible that perception of social support and perceived mental healthcare needs could be an alternate explanation for the current findings. One consistent finding from past studies on physical and mental health is that perception of social support appears to play an influential role more so than the actual availability of social support (Berkman and Krishna 2014; Thoits 2011). The current study emphasizes the continued role of social support from family, friends, and neighbours in increasing the likelihood that an individual will continue to have his or her mental healthcare needs met in the future.

\subsection{Limitations of Findings}

This study also-has some limitations that must be taken into account when interpreting the findings. First, the use of secondary data limits the analysis to those factors for which information is available and therefore excludes other factors that may be considered essential to include in the model. For instance, distance to provider, language of service, and wait times were not available for inclusion in the model. Also, certain populations such as sexual minority groups which are at increased risk of being depressed, having suicidal ideation, experiencing childhood abuse and less likely to have social support could not be examined. Moreover, we were unable to examine the various components of social support (emotional, tangible/instrumental, and informational) individually as noted by some past studies. Second, the cross-sectional nature of the data limits this study's ability to make causal inferences between the explanatory variables and perceived mental healthcare needs. The claims on the temporal order between some of the explanatory variables and perceived mental healthcare needs could also not be established. Thus, only associations can be concluded. Additional data that employ a longitudinal design are needed to further clarify the association between the explanatory variables and perceived mental healthcare needs. Third, this study failed to assess the quality of care received. Finally, most of the information obtained from respondents are self-reported and, thus, may be subject to recall bias. 


\begin{tabular}{|l|lll|}
\hline & Journal : Small 11205 & Dispatch : 29-12-2015 & Pages : 18 \\
& Article No. : 1224 & $\square$ LE & $\square$ TYPESET \\
MS Code : SOCI-D-15-00757 & $\checkmark \mathrm{CP}$ & $\checkmark$ DISK \\
\hline
\end{tabular}

Examining the Independent Effect of Social Support on Unmet...

\subsection{Future Directions}

This study highlights the importance of social support and the value of pursuing additional research in this area to reduce unmet needs. An important area for future study is a closer examination of the characteristics of social support to determine which characteristics are particularly important. This study only examined an overall measure of social support and not specific qualities about the social support an individual receives and how this relates to mental healthcare needs being met. For example, the type, quality, or frequency of social support was not assessed. Examining these factors would provide additional information on the types of social support that can be targeted from a policy standpoint to increase the likelihood that an individual's mental healthcare needs are met.

\section{Conclusion}

In conclusion, this study found that barriers still exist in meeting the mental healthcare needs of Canadians. It is important to develop mental healthcare policies and programs that are appropriate and meet the needs of individuals with mental health-related problems and who are without adequate social support. Other factors identified in this study as associated with unmet mental healthcare needs should also be taken into account when designing programs and policies aimed at reducing unmet mental healthcare needs.

\section{References}

Aday, L. A., \& Andersen, R. (1974). A framework for the study of access to medical care. Health Services Research, 9(3), 208-220.

Ammerman, R. T., Peugh, J. L., Teeters, A. R., Putnam, F. W., \& Van Ginkel, J. B. (2014). Child maltreatment history and response to CBT Treatment in depressed mothers participating in home visiting. Journal of Interpersonal Violence. doi:10.1177/0886260514556769.

Andersen, R. M. (1995). Revisiting the behavioral model and access to medical care: Does it matter? Journal of Health and Social Behavior, 36(1), 1-10.

Andersen, R., \& Newman, J. F. (2005). Societal and individual determinants of medical care utilization in the United States. Milbank Quarterly, 83(4), 1-28.

Baiden, P., den Dunnen, W., Arku, G., \& Mkandawire, P. (2014). The role of sense of community belonging on unmet health care needs in Ontario, Canada: Findings from the 2012 Canadian Community Health Survey. Journal of Public Health, 22(5), 467-478.

Baiden, P., Fallon, B., den Dunnen, W., \& Boateng, G. O. (2015). The enduring effects of early childhood adversities and troubled sleep among Canadian adults: A population-based study. Sleep Medicine, 16(6), 760-767.

Berkman, L. F., \& Krishna, A. (2014). Social network epidemiology. In L. F. Berkman, I. Kawachi, \& M. M. Glymour (Eds.), Social epidemiology (pp. 234-289). New york, NY: Oxford University Press.

Bradley, E. H., McGraw, S. A., Curry, L., Buckser, A., King, K. L., Kasl, S. V., et al. (2002). Expanding the Andersen model: The role of psychosocial factors in long-term care use. Health Services Research, 37(5), 1221-1242.

Bryant, T., Leaver, C., \& Dunn, J. (2009). Unmet healthcare need, gender, and health inequalities in Canada. Health Policy, 91(1), 24-32.

Canada Health Act. (1984). Canada Health Act, RSC 1985, c C-6. http://canlii.ca/t/51w33. Accessed on March 18, 2014.

Cacioppo, J. T., Hughes, M. E., Waite, L. J., Hawkley, L. C., \& Thisted, R. A. (2006). Loneliness as a specific risk factor for depressive symptoms: Cross-sectional and longitudinal analyses. Psychology and Aging, 21(1), 140-151. 


\begin{tabular}{|l|llll|}
\hline & Journal : Small 11205 & Dispatch : & $\mathbf{2 9 - 1 2 - 2 0 1 5}$ & Pages : 18 \\
& Article No. : $\mathbf{1 2 2 4}$ & $\square$ LE & $\square$ TYPESET \\
\hline
\end{tabular}

P. Baiden et al.

486

Caron, J. (1996). The scale of social provisions: Their validation in Quebec. Sante Mentale Au Quebec, 21(2), 158-180.

Carr, W., \& Wolfe, S. (1976). Unmet needs as sociomedical indicators. International Journal of Health Services, 6(3), 417-430.

Cavalieri, M. (2013). Geographical variation of unmet medical needs in Italy: A multivariate logistic regression analysis. International Journal of Health and Geography, 12(27), 1-11.

Cohen, S. (1988). Psychosocial models of the role of social support in the etiology of physical disease. Health Psychology, 7(3), 269-297.

Cohen, S., \& Lemay, E. P. (2007). Why would social networks be linked to affect and health practices? Health Psychology, 26(4), 410-417.

Cohen, S., \& Wills, T. A. (1985). Stress, social support and the buffering hypothesis. Pscyhological Bulletin, 98(2), 310-354.

Conn, K. M., Swanson, D., McQuaid, E., Douthit, K., \& Fisher, S. G. (2015). The relationship between helplessness and the child's asthma symptoms: The role of social support. Journal of Asthma, 52(2), $135-145$.

Coomber, K., \& King, R. M. (2012). Coping strategies and social support as predictors and mediators of eating disorder carer burden and psychological distress. Social Psychiatry and Psychiatric Epidemiology, 47(5), 789-796.

Cutrona, C. E. (1984). Social support and stress in the transition to parenthood. Journal of Abnormal Psychology, 93(4), 378-390.

Cutrona, S., \& Russell, D. (1990). Type of social support and specific stress: Toward a theory of optimal matching. In B. R. Sarason, I. G. Sarason, \& G. R. Pierce (Eds.), Social support: An interactional view (pp. 319-366). New York: Wiley.

Davis, L., \& Brekke, J. (2014). Social support and functional outcome in severe mental illness: The mediating role of proactive coping. Psychiatry Research, 215(1), 39-45.

Dickens, C. M., McGowan, L., Percival, C., Douglas, J., Tomenson, B., \& Cotter, L., et al. (2004). Lack of a close confidant, but not depression, predicts further cardiac events after myocardial infarction. Heart (British Cardiac Society), 90(5), 518-522.

Distelberg, B., \& Taylor, S. (2013). The roles of social support and family resilience in accessing healthcare and employment resources among families living in traditional public housing communities. Child \& Family Social Work, 20(4), 494-506.

Q3 Ellen, I. G., Mijanovich, T., \& Dillman, K. (2001). Neighborhood effects on health: Exploring the links and assessing the evidence. Journal of Urban Affairs, 23(3-4), 391-408.

Eskelinen, M., Korhonen, R., Selander, T., \& Ollonen, P. (2015). Suicidal ideation versus hopelessness/ helplessness in healthy individuals and in patients with benign breast disease and breast cancer: A prospective case-control study in Finland. Anticancer Research, 35(6), 3543-3551.

Fielding, A. H., \& Bell, J. F. (1997). A review of methods for the assessment of prediction errors in conservation presence/absence models. Environmental Conservation, 24(01), 38-49.

Fiori, K. L., \& Consedine, N. S. (2013). Positive and negative social exchanges and mental health across the transition to college loneliness as a mediator. Journal of Social and Personal Relationships, 30(7), 920-941.

Fleury, M., Grenier, G., Bamvita, J., Tremblay, J., Schmitz, N., \& Caron, J. (2013). Predictors of quality of life in a longitudinal study of users with severe mental disorders. Health and Quality of Life Outcomes, 11(92), 1-12.

Gallagher, M., Prinstein, M. J., Simon, V., \& Spirito, A. (2014). Social anxiety symptoms and suicidal ideation in a clinical sample of early adolescents: Examining loneliness and social support as longitudinal mediators. Journal of Abnormal Child Psychology, 42(6), 871-883.

Gerich, J. (2014). Effects of social networks on health from a stress theoretical perspective. Social Indicators Research, 118(1), 349-364.

Granovetter, M. S. (1973). The strength of weak ties. American Journal of Sociology, 78(6), 1360-1380.

Hansen, M. C., \& Aranda, M. P. (2012). Sociocultural influences on mental health service use by Latino older adults for emotional distress: Exploring the mediating and moderating role of informal social support. Social Science and Medicine, 75(12), 2134-2142.

Hawkley, L. C., Thisted, R. A., Masi, C. M., \& Cacioppo, J. T. (2010). Loneliness predicts increased blood pressure: 5-year cross-lagged analyses in middle-aged and older adults. Psychology and Aging, 25(1), $132-141$.

Hewitt, B., Turrell, G., \& Giskes, K. (2012). Marital loss, mental health and the role of perceived social support: Findings from six waves of an Australian population based panel study. Journal of Epidemiology and Community Health, 66(4), 308-314. 


\begin{tabular}{|l|llll|}
\hline & Journal : Small 11205 & Dispatch : & $\mathbf{2 9 - 1 2 - 2 0 1 5}$ & Pages : 18 \\
& Article No. : $\mathbf{1 2 2 4}$ & $\square$ LE & $\square$ TYPESET \\
\hline
\end{tabular}

Examining the Independent Effect of Social Support on Unmet...

545

546

547

548

549

550

551

552

553

554

555

556

557

558

559

560

561

562

563

564

565

566

567

568

569

570

571

572

573

574

575

576

577

578

579

580

581

582

583

584

585

586

587

588

589

590

591

592

593

594

595

596

597

598

599

600

601

602

603

Holt-Lunstad, J., Smith, T. B., Baker, M., Harris, T., \& Stephenson, D. (2015). Loneliness and social isolation as risk factors for mortality: A meta-analytic review. Perspectives on Psychological Science, 10(2), 227-237.

Hosmer, D. W., \& Lemeshow, S. (2000). Applied logistic regression (2nd ed.). New York: Wiley.

House, J. S., \& Kahn, R. L. (1985). Measures and concepts of social support. In S. Cohen \& S. L. Syme (Eds.), Social support and health (pp. 83-108). New York: Academic Press.

Huurre, T., Eerola, M., Rahkonen, O., \& Aro, H. (2007). Does social support affect the relationship between socioeconomic status and depression? A longitudinal study from adolescence to adulthood. Journal of Affective Disorders, 100(1), 55-64.

Ikeda, A., \& Kawachi, I. (2010). Social networks and health. In A. Steptoe, et al. (Eds.), Handbook of behavioral medicine (pp. 237-261). New York, NY: Springer.

Ilse, B., Prell, T., Walther, M., Hartung, V., Penzlin, S., Tietz, F., et al. (2015). Relationship between disease severity, social support and health-related quality of life in patients with amyotrophic lateral sclerosis. Social Indicators Research, 120(3), 871-882.

Kahn, R. L., \& Antonucci, T. C. (1980). Convoys over the life course: Attachment, roles, and social support. In P. B. Baltes \& O. Brim (Eds.), Life-span development and behavior (Vol. 3). New York, NY: Academic Press.

Kang, J. (2012). Pathways from social support to service use among caregivers at risk of child maltreatment. Children and Youth Services Review, 34(5), 933-939.

Kawachi, I., \& Berkman, L. F. (2001). Social ties and mental health. Journal of Urban Health, 78(3), $458-467$.

Kong, F., \& You, X. (2013). Loneliness and self-esteem as mediators between social support and life satisfaction in late adolescence. Social Indicators Research, 110(1), 271-279.

Kunst, M., Bogaerts, S., \& Winkel, F. W. (2010). Domestic violence and mental health in a dutch community sample: The adverse role of loneliness. Journal of Community \& Applied Social Psychology, 20(5), 419-425.

Langeland, E., \& Wahl, A. K. (2009). The impact of social support on mental health service users' sense of coherence: A longitudinal panel survey. International Journal of Nursing Studies, 46(6), 830-837.

LaRocca, M. A., \& Scogin, F. R. (2015). The effect of social support on quality of life in older adults receiving cognitive behavioral therapy. Clinical Gerontologist, 38(2), 131-148.

Lin, C., Li, L., Ji, G., \& Jie, W. (2015). Emotional social support and access to care among older people living with HIV in rural china. International Journal of Geriatric Psychiatry, 30(10), 1041-1047.

Link, B. G., \& Phelan, J. (1995). Social conditions as fundamental causes of disease. Journal of Health and Social Behavior, 35, 80-94.

McLaughlin, E., Lefaivre, M. J., \& Cummings, E. (2010). Experimentally-induced learned helplessness in adolescents with type 1 diabetes. Journal of Pediatric Psychology, 35(4), 405-414.

Moret, L., Nguyen, J. M., Pillet, N., Falissard, B., Lombrail, P., \& Gasquet, I. (2007). Improvement of psychometric properties of a scale measuring inpatient satisfaction with care: A better response rate and a reduction of the ceiling effect. BMC Health Services Research, 7(197), 1-9.

Nausheen, B., Gidron, Y., Gregg, A., Tissarchondou, H. S., \& Peveler, R. (2007). Loneliness, social support and cardiovascular reactivity to laboratory stress. Stress, 10(1), 37-44.

Newall, N. E., Chipperfield, J. G., Bailis, D. S., \& Stewart, T. L. (2013). Consequences of loneliness on physical activity and mortality in older adults and the power of positive emotions. Health Psychology, 32(8), 921-924.

Ong, A. D., Rothstein, J. D., \& Uchino, B. N. (2012). Loneliness accentuates age differences in cardiovascular responses to social evaluative threat. Psychology and Aging, 27(1), 190-198.

Patterson, A. C., \& Veenstra, G. (2010). Loneliness and risk of mortality: A longitudinal investigation in Alameda County, California. Social Science \& Medicine, 71(1), 181-186.

Peck, B. M., Ubel, P. A., Roter, D. L., Goold, S. D., Asch, D. A., Mstat, A. S. J., et al. (2004). Do unmet expectations for specific tests, referrals, and new medications reduce patients' satisfaction? Journal of General Internal Medicine, 19(11), 1080-1087.

Pierce, G. R., Sarason, B. R., Sarason, I. G., Joseph, H. J., \& Henderson, C. A. (1996). Conceptualizing and assessing social support in the context of the family. In G. R. Pierce, B. R. Sarason, \& I. G. Sarason (Eds.), Handbook of social support and the family (pp. 3-23). New York: Plenum Press.

Rhodes, A. E., \& Bethell, J. (2008). Suicidal ideators without major depression: Whom are we not reaching? Canadian Journal of Psychiatry, 53(2), 125-130.

Rowe, J. L., Conwell, Y., Schulberg, H. C., \& Bruce, M. L. (2006). Social support and suicidal ideation in older adults using home healthcare services. The American Journal of Geriatric Psychiatry, 14(9), 758-766. 


\begin{tabular}{|l|lll|}
\hline & Journal : Small 11205 & Dispatch : 29-12-2015 & Pages : 18 \\
& Article No. : 1224 & $\square$ LE & $\square$ TYPESET \\
MS Code : SOCI-D-15-00757 & $\checkmark \mathrm{CP}$ & $\checkmark$ DISK \\
\hline
\end{tabular}

P. Baiden et al.

604

605

606

607

608

609

610

611

612

613

614

615

616

617

618

619

620

621

622

623

624

625

626

627

628

629

630

631

632

633

634

635

636

637

638

639

640

641

642

643

644

Salonna, F., Geckova, A. M., Zezula, I., Sleskova, M., Groothoff, J. W., Reijneveld, S. A., et al. (2012). Does social support mediate or moderate socioeconomic differences in self-rated health among adolescents? International Journal of Public Health, 57(3), 609-617.

Sarason, I. G., Levine, H. M., Basham, R. B., \& Sarason, B. R. (1983). Assessing social support: The social support questionnaire. Journal of Personality and Social Psychology, 44(1), 127-139.

Sarason, B. R., Shearin, E. N., Pierce, G. R., \& Sarason, I. G. (1987). Interrelations of social support measures: Theoretical and practical implications. Journal of Personality and Social Psychology, 52(4), $813-832$.

Shevlin, M., McElroy, E., \& Murphy, J. (2015). Loneliness mediates the relationship between childhood trauma and adult psychopathology: Evidence from the adult psychiatric morbidity survey. Social Psychiatry and Psychiatric Epidemiology, 50(4), 591-601.

Shippee, N. D., Call, K. T., Weber, W., \& Beebe, T. J. (2012). Depression, access barriers, and their combined associations with unmet health needs among publicly insured individuals in Minnesota. Society and Mental Health, 2(2), 85-98.

Sibley, L. M., \& Glazier, R. H. (2009). Reasons for self-reported unmet healthcare needs in Canada: A population-based provincial comparison. Healthcare Policy, 5(1), 87-101.

Siskind, D., Harris, M., Pirkis, J., \& Whiteford, H. (2012). Personalised support delivered by support workers for people with severe and persistent mental illness: A systematic review of patient outcomes. Epidemiology and Psychiatric Sciences, 21(01), 97-110.

Sperry, D. M., \& Widom, C. S. (2013). Child abuse and neglect, social support, and psychopathology in adulthood: A prospective investigation. Child Abuse and Neglect, 37(6), 415-425.

Statistics Canada. (2013). Canadian Community Health Survey-Mental Health: User guide microdata files. Statistics Canada. http://www23.statcan.gc.ca/imdb/p2SV.pl?Function=getSurvey\&SDDS=5015. Accessed on April 12, 2014.

Statistics Canada. (2014). Canadian Community Health Survey (CCHS) Menta Health: Public use microdata file. Derived Variable (DV) Specifications. Statistics Canada http://odesi2.scholarsportal.info/ documentation/CCHS_2012_MH/cchs_mh_derived_variables.pdf. Accessed on April 12, 2014.

Steele, L., Dewa, C., \& Lee, K. (2007). Socioeconomic status and self-reported barriers to mental health service use. Canadian Journal of Psychiatry, 52(3), 201-206.

Sunderland, A., \& Findlay, L. C. (2013). Perceived need for mental health care in Canada: Results from the 2012 Canadian Community Health Survey-Mental Health. Health Reports/Statistics Canada, 24(9), 3-9.

Tabachnick, B. G., \& Fidell, L. S. (2007). Using multivariate statistics (5th ed.). Boston: Pearson/Allyn \& Bacon.

Theeke, L., Horstman, P., Mallow, J., Lucke-Wold, N., Culp, S., \& Domico, J., et al. (2014). Quality of life and loneliness in stroke survivors living in Appalachia. The Journal of Neuroscience Nursing, 46(6), E3-E15.

Thoits, P. A. (2011). Mechanisms linking social ties and support to physical and mental health. Journal of Health and Social Behavior, 52(2), 145-161.

UCLA: Statistical Consulting Group. http://www.ats.ucla.edu/stat/spss/output/logistic.htm Accessed on November 9, 2015. 
Journal : $\mathbf{1 1 2 0 5}$

Article : 1224

\section{型 Springer}

the language of science

Author Query Form

\section{Please ensure you fill out your response to the queries raised below and return this form along with your corrections}

Dear Author

During the process of typesetting your article, the following queries have arisen. Please check your typeset proof carefully against the queries listed below and mark the necessary changes either directly on the proof/online grid or in the 'Author's response' area provided below

\begin{tabular}{|c|c|c|}
\hline Query & Details Required & Author's Response \\
\hline AQ1 & $\begin{array}{l}\text { Dickens et al. (2005) has been changed to Dickens et al. (2004) } \\
\text { so that this citation matches the list. }\end{array}$ & \\
\hline AQ2 & $\begin{array}{l}\text { Conn et al. (2014) has been changed to Conn et al. (2015) so that } \\
\text { this citation matches the list. }\end{array}$ & \\
\hline AQ3 & $\begin{array}{l}\text { References Ellen et al. (2001) and Shippee et al. (2012) are } \\
\text { given in list but not cited in text. Please cite in text or delete } \\
\text { from list. }\end{array}$ & \\
\hline
\end{tabular}

